\title{
SOURCES OF DISSATISFACTION WITH ANSWERS TO THE QUESTION OF THE MEANING OF LIFE
}

\author{
TIMOTHY J. MAWSON \\ University of Oxford
}

\begin{abstract}
In this paper, I seek to diagnose the sources of our dissatisfaction with answers to the question of the meaning of life. I contend that some of these have to do with the question (its polyvalence and persistent vagueness) and some have to do with life and meaningfulness themselves. By showing how dissatisfaction arises and the extent to which it is in-eliminable even by God, I hope to show that we should be satisfied with our dissatisfaction.
\end{abstract}

\section{I.}

'What is the meaning of life?' To ask this question seriously is to know that no answer capable of pithy formulation will be entirely satisfying. 'The meaning of life is to give and receive love.' 'The meaning of life is to gain in wisdom and knowledge.' 'The meaning of life is to find union with God.' 'The meaning of life is to escape the suffering inherent in the cycle of rebirth.' At the stage of seriously asking the question of the meaning of life, one will already have heard and rejected these and a multitude of alternative answers, rejected them at least as definitive of, as saying all that there is to be said about, life's meaning. If one picks through the scrap pile of answers one has thus generated, of most puzzlingly melancholic interest amongst them will be any which one found wanting in completeness whilst believing that there was nevertheless unsurpassable value in the modes of life that they licensed - for example, if one believes in God, the answer involving union with Him; if one believes in suffering inherent in a cycle of rebirth, the answer involving escape from this cycle.

In the case of a religious answer, if one is oneself of that particular religious persuasion, one naturally hesitates in having the thought 'There 
must be more to it than that' when one reaches the object of ultimate religious reverence. If one believes in God, for example, one inclines to worry that the thought must finally be misplaced here, as there could be no 'that' more impressive - more ultimately satisfying of every valuable aspect of one's being - than union with God. But I speculate that one thinks the thought nonetheless, even here. And I speculate that the same goes, mutatis mutandis, if one is of another religious persuasion. If one believes in the 'noble truth' that all existence is characterized by suffering and has committed oneself to the 'noble eightfold path', which one believes will lead one ultimately to escape from it, this too, I hazard, strikes one as, even if complete and sufficient as a guide to life, incomplete and insufficient as an answer to the question of the meaning of life. Of course, if one eventually finds oneself face-to-face with God, one will not, at that time (if time may still be spoken of in such a context), be thinking, 'There must be more to it than this'; and if one ultimately escapes existence altogether, one will not be able in such a non-state to think anything at all, so a fortiori one will not then be thinking 'There must be more to it than this'. But the fact that, in such states/non-states, such thoughts would be obliterated does not make any less well-grounded now the thought in question, for the thought is not that such things cannot happen or that their happening wouldn't then remove any dissatisfaction one might feel about one's life and indeed everything else, but rather that ending up at such points cannot be all that there is to making meaningful the lives that led up to them.

My purpose in this paper is to explain the persistence of this dissatisfaction with answers - even religious answers - to the question of the meaning of life. The first step in my explanation is the claim that there are several legitimate meanings of 'meaning', and indeed of 'life', and thus when one asks 'What is the meaning of life?', one asks an ambiguous question, or - perhaps better - one asks an assemblage of largely overlapping, but significantly different, questions at once. To list but a few of the concerns which find their home in the question:-

One is asking what, if any, consequences there are of an aspect or period of an individual's life, the individual's life as a whole, humanity's life, or life per se. One is asking what, if any, purposes are served (or exist whilst failing to be served) by life in one or more of these senses. One is 
asking what significance, if any, in a greater (potentially non-purposive) scheme of things life in one or more of these senses has. 'Why are we here?' 'Why am $I$ here?' One is asking what, if any, ideals are instantiated in an aspect or period of a life or life in one or more of the larger senses 'What, if anything, does it 'stand for'?' One is asking what, within life in one of these senses, is desirable or valuable in itself, what - if anything makes life worth living, worth going on with, for the individual or group living it. One is asking whether or not life in one or more of these senses contributes positively to various sorts of extrinsic value in the world or beyond. One is asking whether it is in some sense emotionally or spiritually satisfying, or perhaps the proper object of such an emotion/mood even if it is not yet had.

These are just some of the questions that find expression in 'What is the meaning of life?' Having merely briskly stated only some, my hypothesis of polyvalence is not justified in anything but the most impressionistic of ways. But I trust that each of the questions in the previous paragraph will have elicited in the reader a thought that might gain expression in 'Yes, that is in part what I was asking when I asked "What is the meaning of life?" and thus have supported the hypothesis.

The hypothesis of polyvalence gives us a partial explanation of our dissatisfaction with the answers to 'the' question of the meaning of life. If there are indeed so many questions of the meaning of life, it is no wonder that no pithy formula can contain the answer to all of them. When one realizes the polyvalence of the question, one must then have some sympathy with the sages whose answers one has discarded as unsatisfying in coming to the point of this realization.

Consider the predicament in which a sage finds himself or herself when asked, 'What is the meaning of life?' Insofar as he or she is able to make determinate sense of the question and not retreat into Delphic aphorism by way of answer, he or she must disambiguate it in what strikes him or her as the most profound way and then answer it under that interpretation. Perhaps he or she then answers it correctly under that interpretation, but - be that as it may - as, depending on how it is disambiguated, 'the' question of the meaning of life is answered correctly with very different answers, so each particular answer proffered by a sage is likely to strike any individual hearer of it as at best only partial. And so 
it is that even when one thinks of a sage as having singled out something of value in life with his or her answer (perhaps even having singled out something of unsurpassable value), one cannot help but think that whatever it is that he or she has described cannot be all that there is to making life meaningful - 'There must be more to it than that.' And so it is that this thought that one cannot help but have is right.

Polyvalence also explains another thought which I hazard occurs with great frequency in response to the many answers proffered to the question by sages past and present: 'There's something in that'. Perhaps almost as frequently as one feels oneself dissatisfied with a particular answer, one thinks of the unsatisfactory answer as nevertheless having some cogent truth contained within it. If there is a God and he is as those who believe in him characteristically suppose, the meaning of life is unlikely, one supposes, to have nothing whatsoever to do with finding union with him. If ultimate reality instead consists of suffering inherent in a cycle of rebirth, then the meaning of life is unlikely, one supposes, to have nothing whatsoever to do with escaping from this cycle. Whatever one's religious views or lack of them, gaining in knowledge and wisdom, giving and receiving love, and a host of other things which have been offered by sages as keys to the meaning of life are, one will almost certainly believe, valuable and, believing this, one will suppose that it is unlikely that they are entirely irrelevant to the question of life's meaning. No answer to the question of life's meaning that has been propounded by sages is wholly satisfactory, but few are wholly unsatisfactory either. Again then, the hypothesis of polyvalence explains how this is so.

If the claim of polyvalence is correct, then the methodology that must suggest itself in investigating 'the' question of the meaning of life is as follows:-

We should disambiguate the various meanings of 'meaning' and 'life' as they figure in our minds as we ask the question of life's meaning. We should show how, under the various interpretations of 'the' question we are hence enabled to disaggregate, we are or are not in a position to judge of life that it has meaning or does not have meaning and perhaps the extent to which it has or does not have meaning. And, finally, in those senses of the question where we are in a position to make judgements of the meaningfulness of life, we should make those judgements, give the answers. But there will be problems implementing this procedure. 
II.

As someone asking the question of the meaning of life, even asking it seriously and after much thought, it is unlikely one will have a secure and detailed prior grasp of the various different things one is asking. Were one to be given a list of possible interpretations of the question by the person to whom one was asking it and asked by him or her to specify some or all of the interpretations from that list as the meaning or meanings one already had in mind, one would not be able to compare the list one had just been given with a pre-existent list of one's own, and quickly tick off various meanings. Rather, a more synergistic process would take place between the list one had been given on the one hand and one's own, somewhat ill-formed, prior thoughts on the other. One would find oneself saying things like, 'You know, I hadn't really thought about it, but, now I see it there on your list, I think that meaning $a$ is a part of what I was asking, or - perhaps better - a part of what I now wish to ask about when I put to you again the question of the meaning of life.' Look back at the list of questions which I briefly gave as illustrative of those that find expression in 'What is the meaning of life?' I hazard you will have this sort of reaction to at least some of them.

There are of course limits on the interpretations that the question of the meaning of life may carry, limits imposed by quite general considerations concerning the nature of language. As with all other questions, there are sorts of linguistic behaviour which someone might display in response to the question of the meaning of life that would be taken by all competent language-users as indicative, not of having a particular and perhaps unorthodox - interpretation of the question, but rather as indicative of not understanding it at all. So, we need not make space at the table for all comers, indeed we should exclude some 'meanings'. The next question then is, how shall we decide who to exclude?

First, and least controversial as a criterion for exclusion, the interpretations of the question must be logically coherent before we consider them; there are many meanings to the question, but there are no meaningless meanings. That's the thing about meanings, they have to mean something; and that's the thing about logical incoherence, it fails even to mean something. We need not make space at the table then for those 
'sages' who tell us that they are going talk about the meaning of life but speak only gibberish thereafter.

Whilst, as a criterion for exclusion, logical incoherence is uncontroversial, quite who this criterion excludes when applied properly is sometimes controversial. Thus matters are not quite as clear cut when it comes to applying this criterion in practice as one might initially have hoped given its clarity in principle. For example, Sartre contends that interpretations and answers to the question of the meaning of life which involve God involve logical incoherence; thus, he would maintain, they need not even be considered. However, other serious thinkers contend that it is Sartre's answer to the question of the meaning of life which is incoherent and thus not needful of consideration. And we shall thus have to do some philosophical work to decide if either or both deserve a seat at the table in due course.

Secondly, and potentially more controversial as a criterion for exclusion, the interpretation of the question has to address at least an aspect of our concerns when we ask the un-disambiguated question, 'What is the meaning of life?' Of course, if the claim of polyvalence is right, any particular answer will address these concerns only partially. But interpretations must at least address some aspect of our concerns in raising the initial question if they are to be considered further as interpretations of and putative answers to that question rather than, at best, answers to other questions which are beside our concerns when we inquire into the meaning of life.

Even with these two criteria in play, setting some parameters on what will be acceptable as disambiguations of the question of the meaning of life, a worry may linger. The wisdom of sages seeking a place at the table is not left unchallenged; each has to be minimally coherent in the interpretation they give to the question and in their answer to it and the interpretation they offer has to address at least some aspect of the concerns of those of us who ask the 'raw' question. But this still leaves unchallenged the 'wisdom of the crowds', as it were, the wisdom of the rest of us who are asking the question. Might we not worry then that we've set the table up in the wrong place, that the real meaning of the question 'What is the meaning of life?' is, for all we know, something entirely different from what we, the vast majority of competent language-users, take it to be? Perhaps, unbeknownst to us in the crowd, the question 'What is the 
meaning of life?' really does mean something to which the answer is or might be ' 42 '. But such a worry makes no sense; such a thought gestures hopelessly towards no genuine possibility.

Someone who maintained that when people ask 'What is the meaning of life?' they are really asking - even if only in part - a question to which 42 might be the answer, would not have given the question of the meaning of life any legitimate interpretation. How can we be so sure? Because it is we, the crowd asking the question, who create the identity of the question with those concerns; they are our concerns and so we are authoritative over them and the question they form. Even in the case of a polyvalent question such as this - where there is no single hegemonic interpretation, but rather a family of legitimate interpretations - which of the potentially infinite number of interpretations counts as a legitimate member of the finite family is something which is determined by the reflective responses of the competent language-users posing the original question. Words must mean what their users characteristically take them to mean and thus the question of the meaning of life, even if ambiguous, cannot mean something which it is obvious to every competent language-user it does not mean, even partially. And one thing which it is obvious, comically obvious indeed, to us that the question 'What is the meaning of life?' does not mean, even partially, is any member of the set of questions to which ' 42 ' might be an answer. (We, the crowd, are sovereign over the identity of question, but of course we are not sovereign over the identity of the answer to it, or at least it would require another and more controversial argument to establish that we were. Legitimate interpretations of questions are legitimate just in virtue of being taken to be so by competent language-users. But correct answers to questions are not correct (or at least not usually correct) just in virtue of being taken to be correct by competent language-users.)

All of this, it may be admitted, has painted the picture in rather too stark a contrast of black and white. There will be some sages seeking a place at the table who we can clearly see are speaking to an aspect of our concerns ('It's to grow in wisdom and knowledge'; 'It's to find union with God'), and there will be some who we can clearly see are not ('It's 42 '). But there will also be those for whom this issue is not determinate. Sometimes this indeterminacy will be epistemic, capable in principle of being removed by further interrogation of the person giving the answer. 
But sometimes it will not. There will remain a certain amount of indeterminacy even after the most careful reflection and synergistic interaction with them, as a result of what we might call 'persistent vagueness' in our question. To some then we shall ultimately wish to say something along the lines of, "Well, that's "sort-of" an aspect of what I was getting at when I asked the question of the meaning of life'. Some interpretations of the question, we might say, seize on that which is central to our concerns when we ask it; others, on what is more peripheral; and, at the outermost perimeters of the question, the borderlands of the concerns we express when we ask 'What is the meaning of life?' and thus the legitimacy of interpretations of it and the cogency of answers to it are not clearly marked. This is the second source of dissatisfaction with answers to the question of the meaning of life, persistent vagueness in the original question.

Whilst it undoubtedly complicates matters, in itself persistent vagueness is not unprecedented or even particularly troublesome. Persistent vagueness of a similar sort arises over many issues and, as with polyvalence, to be forewarned about it is usually sufficient to be adequately forearmed against it. Indeed seldom does it significantly impede progress even when one is not forewarned. Of course one may find oneself feeling dissatisfied with the somewhat vague results that are all that can - even in principle - be obtained in response to a vague question, but insofar as one realizes that this feature of the answer/answers is a function of persistent vagueness in one's original question, one will become satisfied with any dissatisfaction arising from this source; one will stop thinking, 'There must be more to it than that'. (This sort of satisfied dissatisfaction is analogous then to the comprehensible incomprehensibility that Kant claims is the best we can expect when investigating the relationship between the noumenal and phenomenal self.)

'So is that it?' one might now ask. 'If we disaggregated the various legitimate meanings of the question of the meaning of life, legitimate by reference to appearing, even if only on synergistic reflection, to speak to at least some aspect of our concerns when we raised the original question of life's meaning; if we appreciated the centrality of the concerns raised by these interpretations relative to our reflective understanding of our concerns when asking the original question (taking into account persistent vagueness); if we discovered in turn the answers to each of the questions into which the original was thus 'broken down' or discov- 
ered why answers to these sub-questions were not available to us; if we did all that, would we then reach a completely satisfying (or 'satisfyingly dissatisfying, as we put it) answer to the question or rather then a list of answers to the list of questions - in any case, one which didn't leave us thinking, “There must be more to it than that"?

III.

Baggini approaches the question of the meaning of life in a similar fashion to that suggested heretofore and indicates that he would be favourably disposed to the thought that this would indeed be sufficient. He says this of his approach:-

[It is] 'deflationary', in that it reduces the mythical, single and mysterious question of 'the meaning of life' to a series of smaller and utterly unmysterious questions about various meanings in life. In this way it shows the question of the meaning of life to be at the same time something less and something more than it is usually taken to be: less because it is not a grand mystery beyond the reach of most of us; and more because it is not one question but many. ${ }^{1}$

This is not the view of this paper. Whilst I concede that Baggini is right that the question of the meaning of life may be broken down into other questions, he is wrong in what he thinks flows from this. Many of these other questions are not in any significant way 'smaller' than the original question. Some at least are mysterious and seem destined to remain so for the foreseeable future. And there is sadly more work to be done than drawing up a chart with answers to all of them or blank spaces for the mysterious ones if we are to reach as satisfactory an answer to the question of the meaning of life as is possible. This is because polyvalence and persistent vagueness in the question are not the only sources of dissatisfaction with answers to 'it' and thus removing ambiguity and proffering various answers to the various questions into which 'it' is broken down to whatever degree of determinacy the persistent vagueness permits,

${ }^{1}$ J. Baggini, What's it All About? Philosophy and the Meaning of Life (London: Granta, 2004), 3 
or explaining in particular cases why such answers are unknowable to us, will not remove all such dissatisfaction. Having broken the question down into its component parts, we shall find ourselves with good reason to suppose that these parts need to be put back together again; with reason to think that they need to be put back together again in the right way; and with reason to think that judging the right way is not going to be an easy task. Let us skip ahead in our imagination to the end of the process of disambiguating the question and answering 'it' to locate the sources for dissatisfaction additional to the two on which we have focussed thus far.

Let us imagine then that we have in front of us a summary of our findings, laid out in the form of a chart. Down one side is a complete list of the different legitimate meanings that can be given to the question 'What is the meaning of life?' and, alongside each one, we have either a philosophically satisfying explanation of why we are not in a position to answer the question as so interpreted, one which explains why it must remain in this sense mysterious, or a philosophically satisfying argument for why a particular answer is the one we have best reason to believe is the correct answer to the question as so interpreted. Over at least some sections of this chart the issue of persistent vagueness will have made itself felt. It is difficult to know how this should be represented in our imagination. Nevertheless, let us imagine that the chart has been completed and now stands in front of us awaiting our inspection. What will we find as we look at it?

First, whilst in advance of actually having conducted the investigation that has led us to be able to draw up such a chart, we cannot be sure that each of the entries in it will not strike us as equally cogent to our undifferentiated concerns as expressed in our original question, 'What is the meaning of life?', we rightly suppose that they will not. As already mentioned, some of the interpretations of our question which we may, on reflection, have allowed through as legitimate we may have done so whilst nevertheless marking them down as less central to our concerns than others. We shall hence wish to 'rank' entries in the chart, at least roughly (persistent vagueness will prevent a completely determinate ordering). We might think of those higher up the chart as being the senses of the question which are determinately more central than those lower down. 
Secondly, whilst in advance of actually conducting the investigation that has led us to such a chart we cannot of course be sure that these answers to the question will not be completely separate - causally, metaphysically, and conceptually - from one another, we rightly suspect that they will not be. And this issue generates more difficulties than the first. Even before conducting our investigation into the various meanings of 'the' question of the meaning of life, it is hard to believe that it is a mere accident of language that has resulted in all these meanings being carried by what is, on the surface, one question. And, if we were to conduct the investigation, we would see that this suspicion is well grounded.

As we unpacked these various meanings, we would notice various sorts of relationship between the different senses in which life (in its various senses) may or may not be meaningful. These relationships mean then that the original question cannot be broken down into other questions the answers to which are then left entirely loose and separate from one another, to be ordered in the chart merely by reference to their individual centrality to our original concerns when raising the question of life's meaning. As we looked down the chart, we would find relationships such as the following: an individual's life can only have meaning in sense $p$ if it also has meaning in sense $q$; but it can only have meaning in sense $q$ if humanity's life in general has meaning in senses $q$ and $r$. And so on. These sorts of relationships then might, on reflection, lead us to wish to 'pull up' or indeed de facto 'push down' some things on such a chart. A new iteration of what we have called the 'synergistic' interaction between question and answer would need to be undertaken as a result of one finding oneself wanting to say things like, 'I would have said that meaning in sense $p$ was not very central to my concerns, whereas meaning in sense $q$ was really central, but now I realize that one's life having meaning in sense $p$ is a necessary condition of its having meaning in sense $q$; I shall need to revisit that issue.' Indeed 'revisit' seems unlikely to be quite the right term; 'visit' seems likely to be more appropriate: there is likely to be even more persistent vagueness at this stage in the process of re-ordering the chart than there was at the first, as it is even less likely that one will have a clear prior idea of how important and thus immovable by synergistic interaction one regards the centrality or lack of centrality of the various meanings one now finds related to one another. (However, on the plus side, some of the vagueness that 
was persistent at the earlier stage might be removed at this one. For one might find oneself saying something like, 'I would have said that meaning in sense $x$ was only 'sort of' something I was asking about when I asked the question of life's meaning, but now I see that it is so closely related to meaning in sense $y$, which I'd always thought of as very central indeed, I see that it too really is a central part of my concerns; some of the indeterminacy I had thought of as persistent vagueness at an earlier stage in my investigation into life's meaning now disappears.') Whilst the extra level of vagueness in itself might leave one feeling dissatisfied anew with the results as they now found themselves re-ordered on the chart, again, as at the earlier level, reflection on the source of this (vagueness in one's original question) should lead one to feel satisfied with any such dissatisfaction so arising. However easily one reconciles oneself to this dissatisfaction, one would not be done with reasons for dissatisfaction even yet. Moving on then.

\section{IV.}

Some of the relationships which investigation revealed would enable mutual support of differing kinds between differing sorts of meaningfulness or meaningfulness of the same sort when held by life at different levels of generality (a period or aspect of an individual's life, an individual's life as a whole, humanity's life, or biological life per se); these would draw together into clusters senses in which life in one or more of its senses could be meaningful. But some would not. Some would do the opposite; they would drive wedges between differing senses in which life in one or more of its senses could be meaningful. It is from this point - that some would do the opposite - that yet another spring of potential dissatisfaction bubbles up: as we redrew the chart, we would realize that there is no way for life in every sense of the term to be fully meaningful in every sense of the term and this is a qualitatively new source of dissatisfaction, in that it is dissatisfaction stemming from one's appreciation of a feature of life, not a feature of the question one is asking about it. To become satisfied with one's dissatisfaction with answers to the question of the meaning of life as they emerge from this source then would require a different move from any canvassed heretofore. Fortunately, such a move can be made. 
But these are issues on which we need to spend a moment or two if we are ever to be satisfied with the dissatisfaction which stems from them.

In his lecture 'L'existentialism est un humanism', Sartre hit upon a sense of meaningfulness in which, I suggest, life can only be fully meaningful in a Godless universe. Sartre overstates his case in that if there is a God, our positions mightn't yet be akin to that of paperknives (objects the function of which is entirely determined by factors exterior to them); they might be more akin to those of Executive Vice-Presidents than 'Junior Widget Affixers' and thus we still have at least some meaning in Sartre's sense of meaning - self-creative autonomy. But we cannot have as much meaning in Sartre's sense as we could have had were Atheism true. We won't be 'self-employed', as it were, free to style ourselves as President, Chairman of the Board, and anything else that might catch our fancy. At the most fundamental level - like it or not, realize it or not - we will be 'working' for someone else. This lack of ultimate self-creative autonomy is not something that theistic religions can fairly be accused of having hidden from us as an implication of their worldview. Following a law one believes to have been written by God on tablets of stone thousands of years before one's birth; following someone one believes to have been the perfection of that law, the incarnation of God; humbly submitting oneself to the commands of God as revealed to his last Prophet: none of these could strike one, even for a moment, as manners of living in which, as Sartre might have put it, one's existence is being supposed entirely to precede one's essence. Rather, each overtly supposes that a pattern has been laid down for us by another, God. This may not perhaps be a pattern for every detail of our lives. But it will be a pattern for at least significant areas of our lives, areas of our lives we may well find ourselves wishing we were more free over, indeed areas which, such religions are also unanimous in teaching, it is in our (at least post-lapsarian) human nature to wish ourselves more free over. For example, each of these religions has slightly different understandings of how marital relations are to be conducted. But these religions speak with one voice on the issue of adultery. It is impermissible; it has not been left up to us to construct for ourselves, should we so choose, an essence whereby we are adulterers, the religion only instructing us to 'live authentically' by whatever choice on this issue we may happen to make. This is, of course, not the case on Sartre's view. Should one so choose, one could go in for 
some 'blue skies' thinking, indeed behaving, in this area as in all others; man being responsible only to himself for his life, he is free to create for himself the essence of an adulterer and live accordingly. Such freedom is denied to those who subscribe to one of the theistic religions and thus very natural human urges will, on occasion, lead such people to feel alienated from certain aspects of the way of life they believe themselves to be compelled to lead.

Let us leave Sartre for now and turn to consider a passage from Tolstoy's autobiographical 'Confessions', a passage where, in telling us of a searing moment of self-realization in his own life, he implicitly reveals a very different understanding of what would be required for life to be meaningful.

I [had] lived for thirty or forty years: learning, developing, maturing in body and mind, and ... having ... reached the summit of life from which it all lay before me, I stood on that summit ... seeing clearly that there is nothing in life, and that there has been and will be nothing. ... Differently expressed, the question is ... "Is there any meaning in my life that the inevitable death awaiting me does not destroy?"2

It is futile to pretend that Tolstoy has not hit on a nerve with these observations. Yet futility has never been a bar to the pretensions of Philosophy. Flew tells us this:-

Tolstoy was one of those inclined to hold, as if this were a necessary truth, that nothing can matter unless it goes on forever; or, at any rate, eventually leads to something else which does. But there really is nothing at all ineluctable, or even especially profound, about this particular value commitment. ${ }^{3}$

Flew is right that things can be meaningful in several perfectly legitimate senses (for example, fulfilling a purpose in some larger scheme of things) even if they do not last forever or do not lead to things which do (the larger scheme might not require such results), but Flew is wrong if he thinks, as he seems to think, that there is no sense of meaning at all

${ }^{2}$ I have rather chopped up Tolstoy's text. The full version may be found in several translations free of charge online, by looking up 'L. Tolstoy, A Confession'.

${ }^{3}$ A. Flew, The Presumption of Atheism (London, Elek Books, 1976), 160-161 
in which death - if it is the permanent cessation of existence - detracts from life's meaning. Consider this passage from Craig:-

If each individual person passes out of existence when he dies, then what ultimate meaning can be given to his life? Does it really matter whether he ever existed at all? It might be said that his life was important because it influenced others or affected the course of history. But this only shows a relative significance to his life, not an ultimate significance. His life may be important relative to certain other events, but what is the ultimate significance of any of those events? If all the events are meaningless, then what can be the ultimate meaning of influencing any of them? Ultimately, it makes no difference. ${ }^{4}$

Craig nicely sidesteps Flew. Craig acknowledges that death as complete annihilation would not eliminate all meaning in the sense of bringing about significant consequence (Craig calls what would remain 'relative significance'), but points out that were everything ultimately to come to nothing, this would remove 'ultimate significance', would in that sense render all that had gone before it meaningless. Tolstoy, and - perhaps in a more nuanced way - Craig have then, I suggest, hit upon a sense in which individual humans' lives, if they are permanently terminated at death and their only effects are those which they have in this world, are meaningless. This is a sort of meaninglessness which can only be eliminated entirely if it is eliminated at the ultimate level. And it can only be eliminated at the ultimate level if a certain type of religious hypothesis is true. It could be eliminated there, for example, were there a God such as the one which Jews, Christians and Muslims worship, a God who preserves and magnifies into eternal life all that is most valuable in our lives as led this side of the grave.

So, if we live in a world where there is no God, then out individual lives are, at least potentially, more meaningful in the sense that Sartre discusses and not ultimately meaningful in the sense that Tolstoy and Craig have in sight. If we live in a world where there is a God, then our individual lives are ultimately meaningful in the sense that Tolstoy and Craig discuss and less meaningful in Sartre's sense. We may conclude then, whatever our religious beliefs or lack of them, that no single indi-

${ }^{4}$ W. Craig, 'The Absurdity of Life Without God', in e.g. E. Klemke (ed.), The Meaning of Life (Oxford: OUP, 2000), 42. 
vidual's life can, by dint of some of the relationships between different sorts of meaningfulness, be fully meaningful in all the senses which we may separate out from one another and reasonably care about. This inescapable feature of life may be unsatisfying to us, but in that - as we have now seen - it is a feature which not even an omnipotent being could remove, we should be satisfied with any dissatisfaction arising from it. Either God's there of metaphysical necessity or He's not there of metaphysical necessity. Thus, of logical necessity, our individual lives cannot be fully meaningful in every sense of the term.

V.

A question now arises. If an individual's life may have more meaning in a particular sense, $x$, only at the expense of its having less meaning in another sense, $y$, is there - sometimes or always - a sense of meaningfulness, $z$, by which the other senses $-x$ and $y$ - may in principle be ranked and it be determined that, say, a life fully meaningful in manner $x$ is, despite that, less 'deeply', as we may put it, meaningful than one only partially meaningful in manner $y$ ? For at least some values of $x$ and $y$, we have reason to suppose that there is in fact such a deeper sense of meaningfulness; we have reason to believe that some lives, which are only partially meaningful in one sense, are more deeply meaningful than others, which in turn are fully meaningful in other, perfectly legitimate, but - our reflective intuitions tell us - shallower senses. We think that the charity worker who knowingly brings minimal but non-negligible good into the world before dying and being forgotten about leads a more deeply meaningful life than the infamous mass-murderer whose crimes are later made subject of much popular culture and give impetus to new legislation on gun-control, even though the killer's life had more meaning in some senses of meaning - significant causal consequence, for example - than the charity worker's life.

Holding in mind this thought, let us return to consider the imaginary chart of the findings that we would reach at the end of an idealized investigation into 'the' question of life's meaning as conducted by the methodology suggested so far. It will be recalled that we are thinking 
of the chart as having one column representing the various legitimate interpretations of 'the' question, the various questions into which the raw question 'What is the meaning of life?' may be broken down. And, beside this, another column, which contains, for each entry in the first, either an explanation of why the question as so interpreted is one we are not in a position to answer or an answer to the question as so interpreted. Up until now, we have thought of the chart as being roughly ordered by what, on some reflection, appears to us to be the centrality of these interpretations to our concerns when asking the original question of the meaning of life (roughly ordered, as there is some persistent vagueness in this ordering as a result of this sort of vagueness in our original question). Despite any vagueness, perhaps some people's charts would end up determinately ordered in different ways from others by this process. When we were considering merely the centrality of interpretations of the question to people's concerns, then, as in general each person is himself or herself the greatest authority on what concerns him or her, so we would appropriately have demurred from saying that at most one of these determinately different orderings was right. But, having moved on from centrality to our raw concerns to the issue of deepness, we now need to be more prescriptive; this is because the most central concern (or really overarching 'uber'-concern) that each of us seriously asking the question of the meaning of life has is plausibly the concern to discover the deepest sense of meaning, and, that being our most central or 'uber'concern, to have our other concerns restructured if necessary in the light of this discovery.

We can see this most readily by imagining ourselves having discovered the deepest sense of meaning, and then looking back from this vantage point on the first steps of the journey that has led us to it. One might then say something like, 'I always thought that meaningfulness in sense $x$ was really central to what I was asking about when I asked about the meaning of life, but as I am now able to see that it is quite a shallow sense of meaning - that sense $y$, for example is far deeper than $x$; I wish then to reverse my initial ordering.' One would not say, 'I realize now for the first time that one's life having meaning in sense $x$ is its having meaning in a shallower sense of meaning than its having meaning in sense $y$, nevertheless it is really meaning in sense $x$ that is what still interests 
me most when I ask, "What is the meaning of life?" So it is that by this stage in the process of investigation the ranking by reflective (but philosophically uninformed), centrality of an interpretation of the question to one's concerns when first asking the question will be displaced by the reflective (and philosophically informed) deepness of the interpretation and answer to the question, by what one now believes one has good reason to suppose should concern one in asking the question. Because there is, after all, an underlying and deeper sense of meaning, a sense which holds together at least some of the shallower senses of meaning which may be disambiguated, and because it is this sense which one would thus say is what one was really most centrally asking about all along when one asked the original question, 'What is the meaning of life?', centrality will be displaced by deepness as a principle of ranking in the final version of the chart of one's findings. But now a new problem arises. When it was just centrality to our reflective, but philosophically uninformed, concerns, we could in general merely defer to the reflective intuitions of competent language-users to resolve such issues insofar as persistent vagueness allowed them to be resolved. But now we are discussing deepness, we cannot do this; the answers to the various questions into which 'the' original question of life's meaning may be deflated are related in various ways and some of the ways in which they are related depend on various metaethical and metaphysical issues, so we cannot, until we have settled those issues, know quite how we should 're-inflate' the question of the meaning of life; certainly the reflective intuitions of competent language-users are not guide enough. The deepest question of the meaning of life is one the precise identity of which and one the answer to which waits on metaethics and metaphysics. That being so, pending the conclusion of substantive work in these areas, we have another reason to expect to continue to be dissatisfied with the answer(s) to the question(s) of the meaning of life; these answers will need to be left related to one another by links which are in some cases hypothetical (e.g. 'If Consequentialism is true, then $y$ is a deeper sense of meaningfulness than $x$; if not, then....; 'If there's a God, then $x$ is a deeper sense of meaningfulness than $y$; if not, then ...; and so on). Is this waiting on metaethics and metaphysics then the final reason for our dissatisfaction with answers to the question of life's meaning? It is not. 
VI.

Let us suppose for a moment that all we have discussed hitherto has been accomplished; we see metaethics and metaphysics sub specie aeternitatis and re-order our findings accordingly; we - for example - decide to push up or pull down our list some senses of meaningfulness, ones which appeared to have a certain place in the list to us at an earlier stage but now, by virtue of a revealed tension, we believe can be seen to be determinately above or below their original position; we re-order now solely according to the principle of deepness, allowing our earlier judgements of centrality to be in some cases misguided, given that our primary purpose when asking the question of the meaning of life was to ask the question of the deepest meaning of life. As we return to look down the chart now, we may put an issue which now faces us as our noticing that meaningfulness in certain senses can only be 'bought' at the expense of meaningfulness in other senses and thus we may wish to think of 'trade offs' between differing types of meaningfulness. Some of these trades offs will have been determined in advance of any choices we may make; for example, the trade off between meaningfulness in Sartre's sense and meaningfulness in the Tolstoy/Craig sense will already have been fixed by whether or not there is a God (or something functionally equivalent in the relevant respects) and to what extent this God (or His equivalent), if $\mathrm{He}$ (it) exists, has fixed our essences, as Sartre would have put it, prior to our existences. But, unless the fact is that there's a God (or some such) who (which) has micro-managed us down to the level of paperknives (as no theists actually believe), other trade offs will be dependent on choices which we remain free to make.

Situations may arise then which raise in one's mind the practical question of how one would be best advised to trade off meaningfulness in one sense for meaningfulness in another if one were to wish to make one's life as deeply meaningful as possible overall. The chart we are now imagining ourselves in possession of will of course be ranked with the deeper senses of meaningfulness higher than the shallower ones, but it would be implausible to say that it was worth sacrificing any amount of a shallower sort of meaningfulness in order to achieve any increase in a deeper one, however slight. So, in addition to deepness, we shall wish to consider what we might call overall meaningfulness and consider how 
best to construct this notion out of the materials to hand. One natural thought to have when considering how to represent this would be to wonder if it might be done mathematically, with some formula describing a function that appropriately weights the different sorts of meaningfulness, giving heavier weightings no doubt to the deeper sorts, and thus combines them into a quantity which we then do best (by the standards of making our lives as overall meaningful as possible) to maximize. But, on reflection, one will wish to resist this natural thought for the following reason.

Whilst, despite certain issues of incommensurability, some 'trade offs' between differing sorts of meaningfulness may indeed be understood more or less straightforwardly mathematically, some sorts of meaningfulness seem to require the eschewing of a strategy of maximization altogether. We may make this point more forcefully by utilizing some of the points that Williams has made in raising the 'integrity' objection to Utilitarianism.

Roughly, we may say that an individual's life has integrity in Williams's sense just if he or she is unwilling constantly to subject his or her everyday commitments to a higher-order principle which instructs him or her to maximize something. A life led without integrity in this sense, would, it must be conceded, have an overriding and unifying worldview, and in that sense be very meaningful: an individual's life is sometimes said to have had great meaning just in virtue of its having had some dominant aesthetic, moral, ideological or religious goal, an overarching long-term project that - by acts of the will on the part of the individual concerned - selected and ordered the lower-order projects to which he or she committed himself or herself. So it is that we can speak of such individuals' lives as a whole as standing for something, exemplifying some unitary value. By way of examples: Gauguin's life stood for the aesthetic imperative; Lenin's for the communist revolution. Even if we look for our example to a Utilitarian on whom Williams's original point would be most pressing, we should concede that his or her life has more meaning through its unwavering commitment to Utilitarianism than the rather more 'morally-feckless' lives led by the rest of us. But two points may be made here. First, Williams would surely argue with plausibility that such a life would be one from which the person living it was inevitably alienated and would thus, at the same time as being meaningful in the 
sense of having a unifying overarching project, fail to be meaningful to the person concerned in other senses. Secondly, this alienation would be all the more pressing an issue were there to be no ideology overarching one's life choices other than the determination to make these choices in the manner which led to one's life being maximally overall meaningful. There is a parallel to be drawn here with the Paradox of Hedonism; those who tried in each of their choices to maximize their lives' overall meaningfulness would end up leading less overall meaningful lives than at least some of those who directly aimed at something else. This being the case, it is at least possible (and I would contend plausible) that the notion of overall meaningfulness, even for one who has all epistemic barriers removed - seeing all relevant metaethics and metaphysics sub specie aeternitatis as we have put it - would not yield a determinate answer for at least some 'trade off' issues and this would be a source of dissatisfaction additional to those we have mentioned heretofore. But we have of course faced parallel issues of indeterminacy before in investigating the meaning of life, and we face similar issues every day, so again we should be satisfied with any dissatisfaction arising from this source (or at least no more dissatisfied with this than we are with everyday issues).

What is more troublesome is that there is another source of dissatisfaction with answers to the question of the meaning of life which stems from a genuinely regrettable feature of our condition, one which we have swept out of view for the last few sides so as to see other features more clearly: this side of the grave at least, we never can reach the position of viewing all the relevant aspects of reality sub specie aeternitatis.

One of the ways in which an individual's life can be more or less meaningless for him or her is the extent to which he or she is disabled by circumstances not of his or her own choosing from doing what seems to him or her reasonable given the beliefs that he or she has. Thus even if we suppose that there is in fact one correct ranking (even if it be partially indeterminate) of differing sorts of meaningfulness and we can discover it (as we cannot) and even if we suppose that two people (or the same person at two times) might agree on this ranking (as they may not), even then, between these two people (or one at two times), if they do not have access to the same facts about the world, there can arise tensions of this sort between different sorts of meaning and thus there be no way for life 
considered as the lives of two or more individuals (or one at two or more times) to be fully meaningful.

By this stage, one is likely to be at least somewhat discouraged. Rather exhaustedly, one might ask, 'Is that, at last, it? If we disambiguated the question; if we got our metaethics, metaphysics, and all relevant facts straight (of course, this is impossible for creatures of our epistemic abilities - at least ante-mortem - and thus there will be problems of the sort generated by differing things making some lives meaningful in the sense of being subjectively reasonable for the persons living those lives from those which make it meaningful in the sense of being objectively reasonable); if we ranked our chart by reference to how, on philosophical investigation, deep these various senses of meaningfulness were revealed to us to be; if we looked at all the trade offs internal to issues of life's meaningfulness; and if we worked out, as determinately as the issues allowed, formulae with which to maximize meaningfulness for those internal trade offs where the notion of maximization was appropriate (whilst appreciating that maximization would not be the right notion to employ at the highest level, for 'integrity'-type reasons, when trying to achieve a life of what we may by then have called overall meaningfulness); if we appreciated the difficulties generated by combining individual lives (with their differing sorts of meaningfulness) into collectivities and across lifetimes; if we did all that, would we then at last find a completely satisfying answer to the question of the meaning of life?'

No. We would not be finished with reasons for dissatisfaction even then. But we would, finally, have found as satisfying an answer as the question of the meaning of life permitted, and thus the dissatisfaction which we would continue to feel would not now take as its proper object the answer which we had before us; it would refocus itself on the question.

VII.

The final reason for dissatisfaction is that, once all the above work had been done (not that, as we have seen, it can be done - this side of the grave at least), we would realize that the question of the meaning of life is not as significant a question as we had hoped it to be. By the stage of 
getting to this answer we would realize if we do not already realize that there are many things in life that we rightly value alongside and in some circumstances above its meaningfulness, even above its overall meaningfulness. We have already seen the issue of trade offs arising internal to considerations of meaningfulness (trading meaningfulness in one sense for meaningfulness in another), but this is a trade off of a qualitatively new kind. It may be better for us, not just if we trade off some meaningfulness in one sense in order to achieve greater meaningfulness in another, deeper, sense, for example, but if we do not lead all-things-considered the most overall meaningful lives that we can lead. A relatively overall meaningful life may well be worse for a person than a relatively overall meaningless one. (Plausibly Van Gogh's life was worse for him than that pictured by P. G. Wodehouse as being enjoyed by Bertie Wooster, but Van Gogh's life was more meaningful in every sense of the term than Wooster's.)

The question of the meaning of life is an important question, but it is not the only important question; it may be in some sense an ultimate question, but it is not the only ultimate question in the sense that the answer to it dictates the answers to all other questions of importance. The meaning of life is not to know the meaning of life and thus even someone who did know the meaning of life better than another might well end up leading a less meaningful life than that other. What is perhaps more surprising, but is also, I suggest, the case, is that a person who knew the meaning of life might end up rationally choosing to lead a less overall meaningful life than that other. This is because the truly wise try first and foremost not to lead meaningful lives, but to lead good ones. But to establish that and to talk about its attendant dissatisfactions would require another paper. ${ }^{5}$

${ }^{5}$ I am grateful for the critical comments of John Cottingham on a draft of this paper. 